\title{
Detection of Human T Cell Lymphotropic Virus Type I Proviral DNA and Its Gene Expression in Synovial Cells in Chronic Inflammatory Arthropathy
}

\author{
Isao Kitajima, Kazuhiko Yamamoto, ${ }^{\star}$ Kazuto Sato, ${ }^{\ddagger}$ Yuko Nakajima, ${ }^{\ddagger}$ Toshihiro Nakajima, \\ Ikuro Maruyama," Mitsuhiro Osame," and Kusuki Nishioka \\ Division of Rheumatology and Molecular Immunology, Institute of Medical Sciences, School of Medicine, St. Marianna University, \\ Kawasaki-shi Kanagawa-ken 216, Japan; *Department of Medicine and Physical Therapy, Faculty of Medicine, University of Tokyo, \\ Tokyo 113, Japan; ${ }^{*}$ Institute of Rheumatology, Tokyo Women's Medical College, Tokyo 163, Japan; and ${ }^{8}$ Third Department of Internal \\ Medicine, Kagoshima University, Kagoshima 890, Japan
}

\begin{abstract}
To investigate the pathogenesis of human $\mathbf{T}$ cell lymphotropic virus type I (HTLV-I)-associated chronic inflammatory arthropathy (HAAP), we sought to detect proviral DNA in the articular lesions. For the detection of proviral DNA, we used the polymerase chain reaction (PCR). Proviral DNA was detected not only in the peripheral blood mononuclear cells (PBMCs) and synovial fluid cells (SFCs), but also in the T lymphocyte-depleted cultured synovial cells (CSCs). These findings suggest that the infection by HTLV-I might occur in vivo in non-T cells. Furthermore, we detected HTLV-I tax $/$ rex $_{1}$ messenger RNA in fresh synovial tissues and CSCs but not in fresh PBMCs and fresh SFCs using reverse transcription and PCR. Immunohistochemically, the CSCs from HAAP patients were also shown to express the HTLV-I antigens. These data indicate that HTLV-I in the non-T synovial cells can be transcribed and expressed. Moreover, the sequences of pXII regions in the CSCs demonstrated 97.5-99.4\% homology to that in MT-2 cells, HTLV-I-infected cell line. This confirmed that the PCR-amplified bands reflect HTLV-I itself. These results suggest that this organ-specific inflammation can be attributed to non-T cell virus infection in articular lesions. (J. Clin. Invest. 1991. 88:1315-1322.) Key words: gene expression • human T cell lymphotropic virus type I (HTLV-I) • HTLV-I-associated arthropathy $\bullet$ polymerase chain reaction $\bullet$ synovial cell
\end{abstract}

\section{Introduction}

Human T cell lymphotropic virus type I (HTLV-I) ${ }^{1}$ is known as an etiologic agent of adult $\mathrm{T}$ cell leukemia (ATL) (1). In this disease a monoclonal genomic integration of proviral HTLV-I

Address reprint requests to Dr. Kusuki Nishioka, Director, Division of Rheumatology and Molecular Immunology, Institute of Medical Science, School of Medicine, St. Marianna University, 2-16-1 Sugao, Miyamae-ku 163, Kawasaki-shi Kanagawa-ken 216, Japan.

Received for publication 26 October 1990 and in revised form 21 May 1991.

1. Abbreviations used in this paper: ATL, adult T cell leukemia; CSC, cultured synovial cell; FST, fresh synovial tissue; HAAP, HTLV-I-associated arthropathy; HAM/TSP, HTLV-I-associated myelopathy/ tropical spastic paraparesis; HTLV-I, human T cell lymphotropic virus type I; PCR, polymerase chain reaction; RA, rheumatoid arthritis; RT, reverse transcription; SFC, synovial fluid cell.

J. Clin. Invest.

(c) The American Society for Clinical Investigation, Inc.

$0021-9738 / 91 / 10 / 1315 / 08 \$ 2.00$

Volume 88, October 1991, 1315-1322
DNA has been demonstrated (2). Recent studies have also revealed an association between HTLV-I and a subset of chronic progressive myelopathy, called HTLV-I-associated myelopathy/tropical spastic paraparesis (HAM/TSP) $(3,4)$. A random integration of HTLV-I proviral DNA has been reported in peripheral blood mononuclear cells (PBMCs) and the cells isolated from cerebrospinal fluid from patients with HAM (5). Although the role of HTLV-I infection in HAM/TSP disorders has not yet been clarified, HTLV-I is thought to be involved in the pathogenesis of such neurological disorders.

Recently, other organ systems besides the nervous system have been reported to be involved in HAM/TSP. Manifestations of their involvement include alveolitis (6), Sjögren syndrome (7), and polymyositis (8). We have also previously reported a case of proliferative synovitis in a patient with chronic ATL (9) and cases of polyarthritis in patients with HAM (10). Furthermore, a chronic inflammatory arthropathy was found to occur in HTLV-I carriers and we have thus likened it to HTLV-I-associated arthropathy (HAAP) (11). However, the pathological association of this arthropathy with the virus remains to be clarified.

To approach this problem, we have attempted to detect HTLV-I proviral DNA in the tissue of this inflammatory arthropathy. We report here that the proviral DNA could be detected not only in T cells but also in non-T cells in the synovium of patients with HAAP. Moreover, viral gene expression was also detected both in the fresh synovial tissues (FSTs) and in $\mathrm{T}$ cell-depleted cultured synovial cells (CSCs). Finally, we have confirmed that the virus is HTLV-I by demonstrating HTLV-I pXII DNA sequences in the CSCs of the HAAP patients.

\section{Methods}

Patients. Two patients with chronic persistent oligo-arthritis in relatively large joints associated with proliferative synovitis were studied. They had anti-HTLV-I antibodies in serum and synovial fluid (SF) as assessed by the particle agglutinin method (ATLA kit, Serodia, Fujirebio, Inc., Tokyo, Japan) (12) and confirmed by Western blot analysis (13). Their clinical profiles were consistent with HAAP (11). Two patients with rheumatoid arthritis (RA) with negative anti-HTLV-I antibodies were also studied.

Cells. PBMCs and synovial fluid cells (SFCs) from two HAAP patients and two RA patients were isolated by Ficoll-Conray gradient centrifugation. FSTs were biopsied from patients' knee joints under arthroscopy. The samples were rinsed well with sterile saline to remove blood components and then immediately frozen into the liquid nitrogen. In order to protect the activation of the viral genes after their transfer to in vitro conditions, we made these sample preparations within $15 \mathrm{~min}$ (14). To obtain nonlymphoid cells from synovial tissues, cells were cultured for short periods. The biopsied synovial tissues were 
minced into small pieces and cultured for $12 \mathrm{~d}$ in RPMI-1640 (Gibco Laboratories, Grand Island, NY) with $10 \%$ fetal calf serum (Gibco Laboratories), $100 \mathrm{U} / \mathrm{ml}$ of penicillin, $100 \mu \mathrm{g} / \mathrm{ml}$ of streptomycin, and $10 \mathrm{mM}$ of Hepes (Sigma Chemical Co., St. Louis, MO). Culture medium were changed every $3 \mathrm{~d}$, and nonadherent lymphoid cells were removed. Adherent synovial cells were maintained in the culture for 12 d. Contamination by CD2-positive (a pan-T cell marker) cells in these adherent cell populations, estimated by immunostaining and then determined by counting, was less than 1 in 10,000 of the CSCs (data not shown). MT-2 cells, a human HTLV-I-infected T cell line, were reported often to contain a number of proviral DNA copies in long-term culture conditions (15). We used MT-2 cells from frozen conditions and cultured for short durations that were confirmed to contain one or two copies of the viral genome in one cell by an EcoRI digesting study (data not shown). These MT-2 cells and PBMCs from an ATL patient were used as positive controls for virus detection and gene expression.

DNA and RNA preparation. Chromosomal DNA was isolated by SDS/proteinase K/RNase A digestion of cells, followed by phenol and chloroform extraction (16), whereas cytoplasmic RNA was isolated by the acid guanidinium thiocyanate-phenol-chloroform extraction method (17). The DNA and RNA concentrations were estimated by measuring the absorbance ratio at $260 / 280 \mathrm{~nm}$.

Detection of the HTLV-I proviral DNA. Polymerase chain reaction (PCR), a procedure for an enzymatic amplification of DNA, was used for detection of the proviral DNA (18). Oligonucleotide primers for PCR were synthesized on a DNA synthesizer (model 380A, Applied Biosystems, Inc., Foster City, CA). The primers used in this study are summarized in Table I. Amplified DNAs included HTLV-I gag (product size: 535 base pairs [bp] [19]), env (327 bp) (19), pX (159 bp) (20), and as an internal control, HLA DQ $\beta$ (238 bp) (21). The PCR reaction mixtures $(100 \mu \mathrm{l})$ included $1 \mu \mathrm{g}$ of DNA sample, $100 \mathrm{pmol}$ of each primer, $400 \mu \mathrm{mol}$ of each deoxynucleotide triphosphate, and $2.5 \mathrm{U}$ of the heat-stable DNA polymerase (Taq) (Perkin-Elmer Cetus, Norwalk, CT) (22). The amplification procedure consisted of 35 cycles of the following steps: (a) $94^{\circ} \mathrm{C}$ for $1 \mathrm{~min}$ for denaturation, (b) $60^{\circ} \mathrm{C}$ for $2 \mathrm{~min}$ for annealing, and $(c) 72^{\circ} \mathrm{C}$ for $3 \mathrm{~min}$ for extension. One tenth of the resultant amplified DNA was then separated in 4\% Nusieve (FMC BioProducts, Rockland, ME) agarose gel electrophoresis and visualized with ethidium bromide fluorostaining. In other experiments, DNAs in agarose gels were blotted on a nylon membrane according to the method of Southern (23). The blotted filters were prehybridized for 12 $\mathrm{h}$ at $42^{\circ} \mathrm{C}$ and then hybridized for $15 \mathrm{~h}$ at $42^{\circ} \mathrm{C}$ with a digoxigenin-1 1 dUTP-labeled genomic HTLV-I probe (24). Detection using the di- goxigenin-labeled probe was performed with an anti-digoxigenin antibody conjugated with alkaline phosphatase. This was visualized using an enzyme-linked color reaction (Boehringer-Mannheim Corp., Mannheim, FRG).

Detection of HTLV-I tax $/$ rex, messenger RNA (mRNA) by reverse transcription (RT) and PCR (RT-PCR). For detection of HTLV-I mRNA, RT-PCR was carried out by the method of Kinoshita et al. (25). Briefly, $1 \mu \mathrm{g}$ of total cytoplasmic RNA was annealed with $200 \mathrm{ng}$ of random hexadeoxynucleotide primers in a total volume of $20 \mu \mathrm{l}$ and was reverse-transcribed with $50 \mathrm{U}$ of avian leukemia virus (ALV) reverse transcriptase at $42^{\circ} \mathrm{C}$ for $1.5 \mathrm{~h}$. The primers (RPX3 and RPX4) (20) for the PCR amplification (Table I) were located upstream and downstream to the second splice junction site of mRNA for the HTLVI tax $1 /$ rex $_{1}$ gene. $\beta$-Actin primers were used as an internal control (Table I; BAC1 and BAC2). The RT-PCR was carried out in 45 cycles with $\operatorname{tax}_{1} / \mathrm{rex}_{1}$ and $\beta$-actin primers as in the same way as described for the detection of HTLV-I proviral DNA. The amplified DNA fragments were $145 \mathrm{bp}$ for the tax $1 /$ rex $_{1}$ gene, and $218 \mathrm{bp}$ for the $\beta$-actin gene. The blotting and hybridization were carried out with the digoxigenin-labeled HTLV-I probe RPXPR1 (HTLV-I location, 5175-5158 and 7302-7312; sequence, AACACCATGGCCCACTTCCC) surrounding the second splice junction site of $\mathrm{mRNA}$ for the $\operatorname{tax}_{1} / \mathrm{rex}_{1}$ gene.

Immunostaining for the HTLV-I antigens. CSCs from both HAAP patients and RA patients were evaluated by immunostaining with monoclonal antibodies. They were fixed with cold acetone for $10 \mathrm{~min}$. The samples were then incubated with the following mouse monoclonal antibodies: anti-CD2 (reactive with pan-T cells, Coulter Immunology, Hialeah, FL), anti-CD14 (reactive with macrophages, Coulter), and anti-CD 20 (reactive with pan B cells, Coulter), GIN 14 (reactive with HTLV-I core protein p19 and p28, Fujirebio, Inc.), NOR 1 (reactive with HTLV-I core protein p24, Fujirebio, Inc.), and F10 (reactive HTLV-I envelope glycoprotein gp 21, Fujirebio, Inc.). After washing with phosphate-buffered saline (PBS), sections were incubated with fluorescein isothiocyanate-conjugated goat anti-mouse (IgG + IgM) antibody.

DNA sequencing of pXII regions of CSCs from HAAP patients. DNAs of CSCs from each HAAP patient and MT-2 cells were amplified with PCR using SK43 and SK44 HTLV-I pXII primers (20) (Table I). Amplified DNAs was subcloned into the pUC 18 vector. The DNA sequence was determined by the dideoxynucleotide method and fluorescence-based automated DNA sequencing (automated DNA sequencing system, model 373A, Applied Biosystems, Inc.) (26). The nucleotide sequences from the CSCs in this study were compared with

Table I. Oligonucleotide Primers Sequences Used in PCR

\begin{tabular}{|c|c|c|c|}
\hline Oligomer & Function & Location & Sequence $\left(5^{\prime}---.---3\right)$ \\
\hline Gag 1 & Primer $(+)$ & $841-846$ & CGACCGCCCCGGGGGTGGCCGCT \\
\hline Gag 2 & Primer (-) & $1375-1353$ & GGTACTGCAGGAGGTCTTGGAGG \\
\hline Env/SG221 & Primer (+) & $5799-5818$ & CTCGAGCCCTCTATACCATG \\
\hline Env/SG227 & Primer (-) & $6125-6106$ & GGATCCTAGGGTGGGAACAG \\
\hline pX/SK43 & Primer (+) & $7335-7354$ & CGGATACCCATGCTACGTGT \\
\hline pX/SK44 & Primer (-) & $7493-7473$ & GAGCCGATAACGCGTCCATCG \\
\hline HLADQ/GH28 & Primer $(+)$ & $25-45$ & CTCGGATTCGCATGTGCTACTTCACCAAGC \\
\hline HLADQ/GH29 & Primer (-) & $245-227$ & GAGCTGCAGGTAGTTGTGTCTGCACAC \\
\hline mRNA/RPX3 & Primer $(+)$ & $5096-5115$ & ATCCCGTGGAGACTCCTCAA \\
\hline mRNA/RPX4 & Primer (-) & $7357-7338$ & AACACGTAGACTGGGTATCC \\
\hline$\beta$-Actin/BACl & Primer $(+)$ & $1471-1490$ & AAGAGAGGCATCCTCACCCT \\
\hline$\beta$-Actin/BAC2 & Primer (-) & $2129-2110$ & TACATGGCTGGGGTGTTGAA \\
\hline
\end{tabular}

Oligonucleotide location of HTLV-I corresponds to the composite prototype HTLV-I proviral gemone (Gene Bank accession no. J02024, references 18 and 19). HLA DQ $\beta$ primers are from Sharf et al. (21) and underlines show a linker. Primers of HTLV-I tax $/ \operatorname{rex}_{1}$ mRNA by RT-PCR are mRNA/RPX3 and mRNA/RPX4 (24). $\beta$-Actin primers were a gift from Dr. Kinoshita and correspond to Gene Bank data base (Humaccyba). 

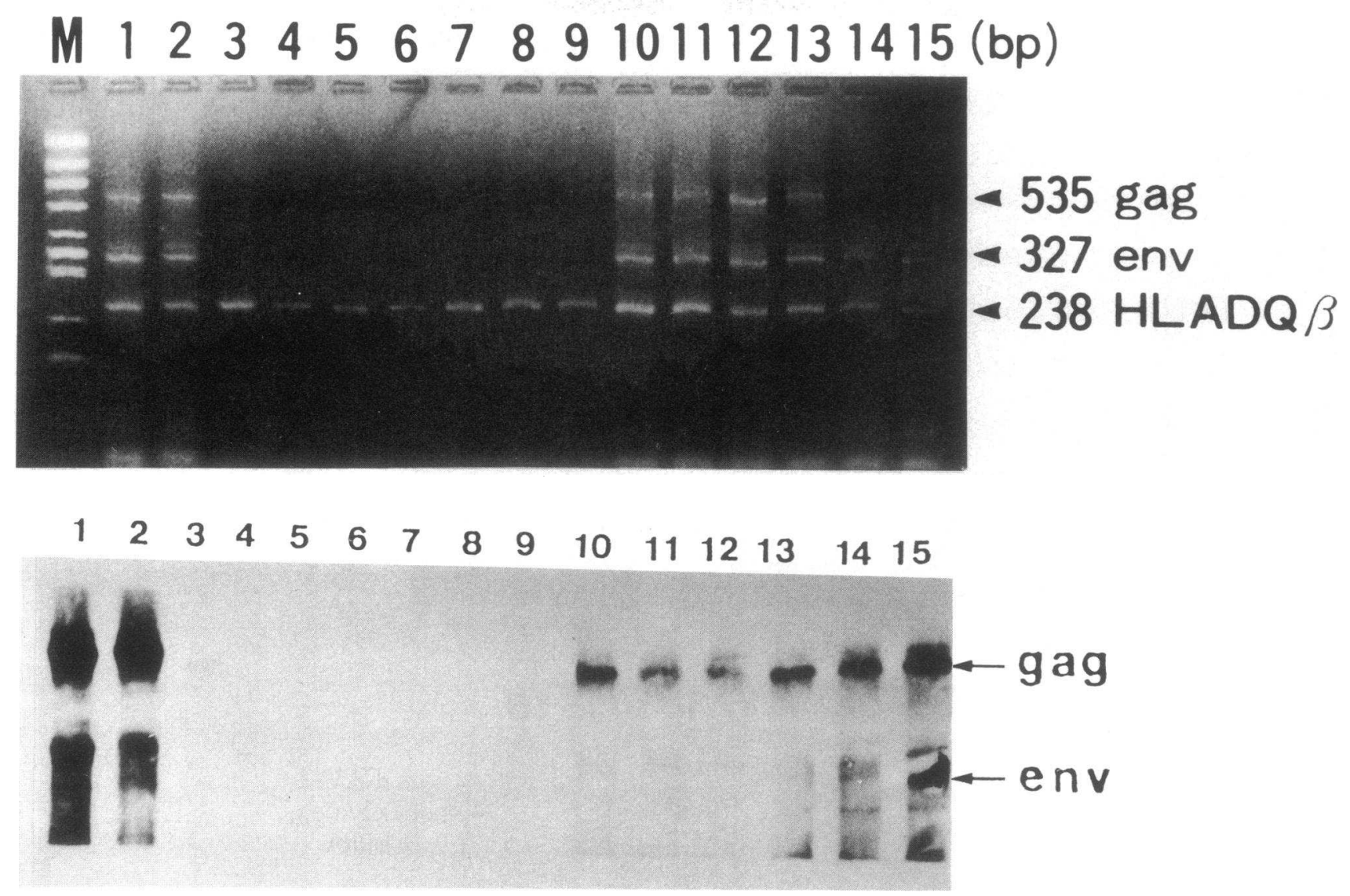

Figure 1. (A) Detection of HTLV-I proviral DNA by PCR. The amplified DNA was electrophoresed in $4 \%$ Nusieve agarose and visualized by ethidium bromide fluorostaining. Three major bands were observed: 535 bp for HTLV-I gag, 327 bp for HTLV-I env, and 238 bp for HLA DQ $\beta$. M, DNA molecular weight marker (X174/HincIl digestion): lane 1 , MT-2 cell; lane 2, PBMCs from an ATL patient; lane 3, $1 \times 10^{-5}$ dilution MT-2 DNA, $10 \mathrm{pg}$ of MT-2 DNA combined with $1 \mu \mathrm{g}$ of HTLV-I-negative DNA; lanes 4 and 7, PBMCs from RA patients; lanes 5 and 8, SFCs from RA patients; lanes 6 and 9, CSCs from RA patients; lanes 10 and 13, PBMCs from HAAP patients; lanes 11 and 14, SFCs from HAAP patients; lanes 12 and 15 , CSCs from HAAP patients. (B) Southern blot analysis of $A$. The amplified DNAs in PBMC, SFCs, and CSCs from HAAP patients hybridized with digoxigenin-labeled genomic HTLV-I probe (lanes 10-15).

those from the established HTLV-I cell line, ATK-I (27) as well as other reported sequences of the viruses of HTLV families, including HTLVII (28) and simian T cell leukemia virus (STLV) (29).

\section{Results}

Detection of HTLV-I proviral DNA. Conventional Southern blot analysis was attempted several times in an effort to detect HTLV-I proviral DNA in the genome of cells from HAAP patients. Although a positive signal was obtained in control MT- 2 cells and PBMCs from an ATL patient, signals from cells of HAAP patients were not detected. Therefore, the possible presence of HTLV-I proviral DNA in these tissues was examined using PCR. The primers used in these studies are listed in Table I. First, to determine the sensitivity of the assay, a titration experiment was performed. MT-2 DNA was mixed with HTLV-I-negative DNA, applied totally with $1 \mu \mathrm{g}$ of DNA, and amplified with the gag and env primers. HTLV-I-specific bands were detectable up to a $1 \times 10^{-5}$ dilution ( $1 \mathrm{pg}$ of MT-2 DNA combined with $1 \mu \mathrm{g}$ of HTLV-I-negative DNA) in a Southern blot using a digoxigenin-labeled HTLV-I full-length probe (data not shown).
Fig. $1 A$ shows the ethidium bromide fluorostaining of PCR-amplified DNAs from patients' cells in 4\% Nusieve agarose gel electrophoresis. When MT-2 cells (Fig. $1 \mathrm{~A}$, lane 1 ) or PBMCs from a patient with ATL (Fig. $1 A$, lane 2) were examined with a mixture of three sets of primers, the amplification of the DNA revealed three major bands: 535 bp for gag, 327 bp for env, and 238 bp for HLA DQ $\beta$. Interestingly, distinct positive amplifications of HTLV-I and HLA DQ $\beta$ were observed in DNAs from PBMCs and SFCs from the two HAAP patients (Fig. $1 A$, lanes $10,11,13$, and 14 , respectively); only the HLA DQ $\beta$ band was observed in DNAs from the RA patients. This result was also confirmed by Southern blot analysis of the amplified DNAs using digoxigenin-labeled HTLV-I probe (Fig. $1 \mathrm{~B}$ ).

Next, we examined T cell-depleted CSCs. The amount of amplified proviral DNA in these specimens was estimated to be about one-fifth of that from MT-2 cells, comparing the intensity of the signals in the Southern blot analysis (Fig. $1 B$, lanes 12 and 15). 1 out of 10,000 contamination by MT-2 DNA in HTLV-I-negative DNA (two methods: mixtures of DNAs, 100 pg of MT-2 DNA combined with $1 \mu \mathrm{g}$ of HTLV-I-negative DNA; DNAs extracted from a mixture of $1 \times 10^{2}$ of MT- 2 cells 

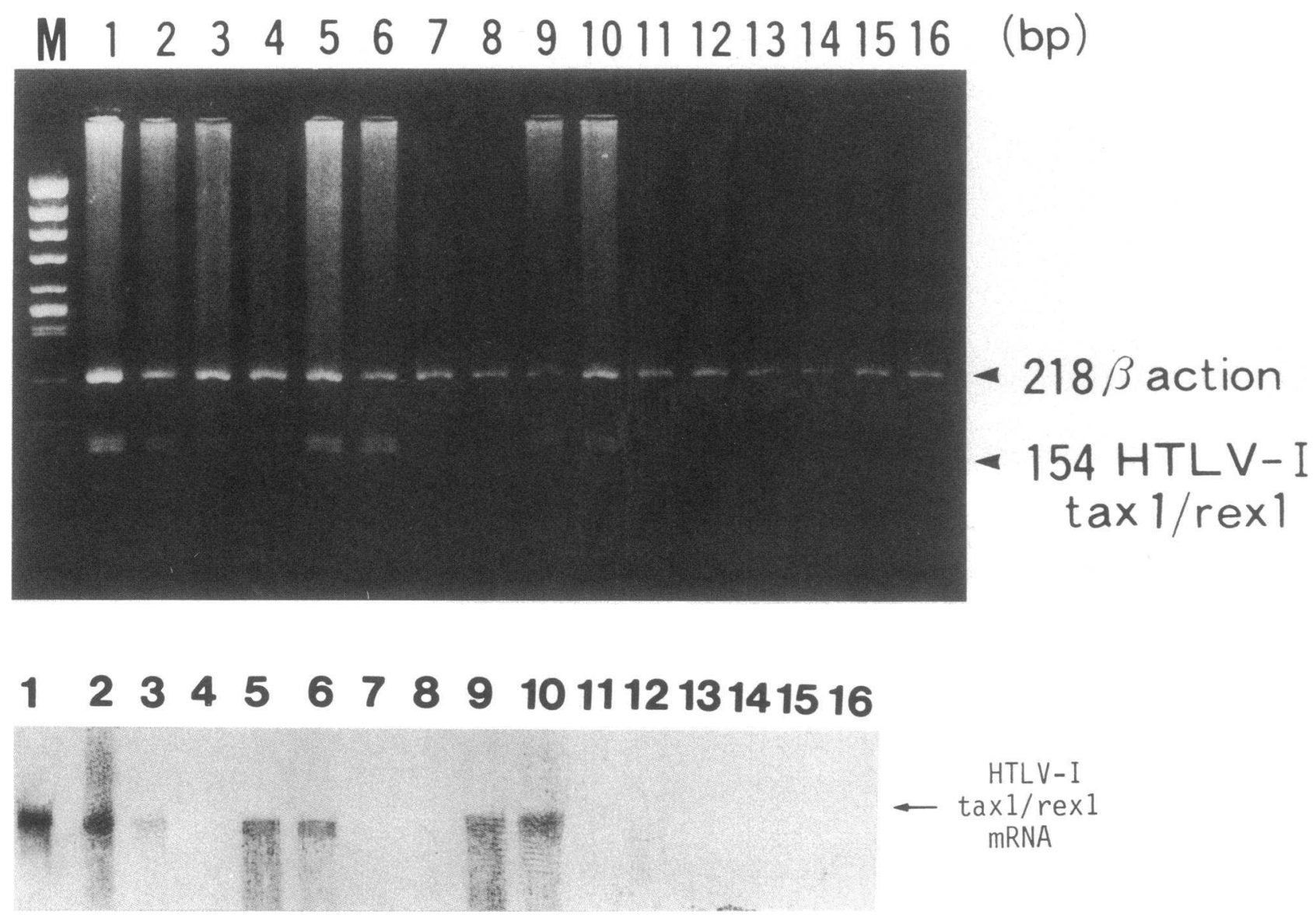

Figure 2. (A) Detection of mRNA for the tax $x_{1} / \mathrm{rex}_{1}$ gene by RT-PCR. The band of specific $\mathrm{mRNA}$ for the tax $1 / \mathrm{rex}_{1}$ of HTLV-I is $154 \mathrm{bp}$ and $\beta$-actin as internal control is $218 \mathrm{bp}$. $M$, DMA molecular weight marker (X174/Hincll digestion): lanes $1-4$, mRNA of MT-2 cells mixed with that of HTLV-I-negative PBMCs (lane $1,1 \times 10^{-3}$ dilution, $1 \mathrm{ng}$ of MT-2 RNA combined with $1 \mu \mathrm{g}$ of HTLV-I-negative RNA; lane $2,1 \times 10^{-4}$ dilution, $100 \mathrm{pg}$ of MT-2 RNA combined with $1 \mu \mathrm{g}$ of HTLV-I-negative RNA; lane 3, $1 \times 10^{-5}$ dilution, 10 pg of MT-2 RNA combined with $1 \mu \mathrm{g}$ of HTLV-I-negative RNA; lane $4,1 \times 10^{-6}$ dilution, 1 pg of MT-2 RNA combined with $1 \mu \mathrm{g}$ of HTLV-I-negative RNA); lanes 5-8, HAAP patient 1 (lane 5, FSTs; lane 6, CSCs; lane 7, fresh PBMCs; lane 8, fresh SFCs); lanes 9-12, HAAP patient 2 (lane 9, FSTs; lane 10, CSCs; lane 11, fresh PBMCs; lane 12, fresh SFCs); lane 13, FSTs from an RA patient; lane 14, CSCs from an RA patient; lane 15, fresh PBMCs from an RA patient; lane 16, fresh SFCs from an RA patient. (B) Southern blot analysis of $A$ using digoxigenin-labeled HTLV-I probe (RPXPRI) surrounding the second splice junction sites of mRNA for the tax $\operatorname{trex}_{1}$ gene. Signals are detected in both FSTs (lanes 5 and 9 ) and CSCs (lanes 8 and 12) from HAAP patients.

and $1 \times 10^{7}$ of HTLV-I-negative cells) only yielded very little signal in PCR followed by the Southern blot (Fig. $1 B$, lane 3).

However, the signals obtained from the CSC DNA, in which contaminating $\mathrm{T}$ cells were removed to be to a frequency of less than 1 in 10,000 cells, were equal to those from the PBMC and SFC DNA, which contained rich T cells. On the contrary, HTLV-I DNA was not found in the amplified DNA of the control RA patients (Fig. 1, $A$ and $B$, lanes 4-9). These results, therefore, indicated that HTLV-I proviral DNA exists in non-T cell CSCs from HAAP patients.

Detection of HTLV-I tax $/$ rex, mRNA by using RT-PCR. We attempted to detect HTLV-I tax ${ }_{1} /$ rex $_{1}$ mRNA in articular tissues of affected patients. Complementary DNA (cDNA) synthesized by reverse transcriptase from RNA from articular tissues was amplified with the RPX3 and RPX4 primers located upstream and downstream from the splicing site. Therefore, in this system, contaminating DNA in these RNA samples could not contribute to the amplified products. Fig. $2 A$ shows the ethidium bromide fluorostaining. Bands of specific $\operatorname{tax}_{1} / \operatorname{rex}_{1}$
mRNA (product size $154 \mathrm{bp}$ ) and $\beta$-actin ( $218 \mathrm{bp}$ ) were observed in MT-2 cells. These were also confirmed by Southern blot analysis using a digoxigenin-labeled HTLV-I probe (RPXPR1) surrounding the second splice junction site of mRNA for the $\operatorname{tax}_{1} / \mathrm{rex}_{1}$ gene (Fig. $2 B$ ). To determine the sensitivity of this RT-PCR, RNA from MT'-2 cells diluted serially with RNA from PBMCs of a healthy individual was tested (Fig. 2, $A$ and $B$ : lane $1,1 \times 10^{-3}$ MT-2 dilution, $1 \mathrm{ng}$ of MT-2 RNA combined with $1 \mu \mathrm{g}$ of HTLV-I-negative RNA; lane 2,1 $\times 10^{-4}$ MT-2 dilution, 100 pg of MT-2 RNA combined with 1 $\mu \mathrm{g}$ of HTLV-I-negative RNA; lane $3,1 \times 10^{-5} \mathrm{MT}-2$ dilution, $10 \mathrm{pg}$ of MT-2 RNA combined with $1 \mu \mathrm{g}$ of HTLV-I-negative RNA; lane 4, $1 \times 10^{-6}$ MT-2 dilution, 1 pg of MT-2 RNA combined with $1 \mu \mathrm{g}$ of HTLV-I-negative RNA).

The signal representing the $\operatorname{tax}_{1} / \mathrm{rex}_{1}$ mRNA was detected in both FSTs (lanes 5 and 9) and CSCs (lanes 6 and 10), but could not be detected in fresh PBMCs (lanes 7 and 11) and fresh SFCs (lanes 8 and 12) from two HAAP patients by gel electrophoresis and Southern blot analysis. In the same studies 

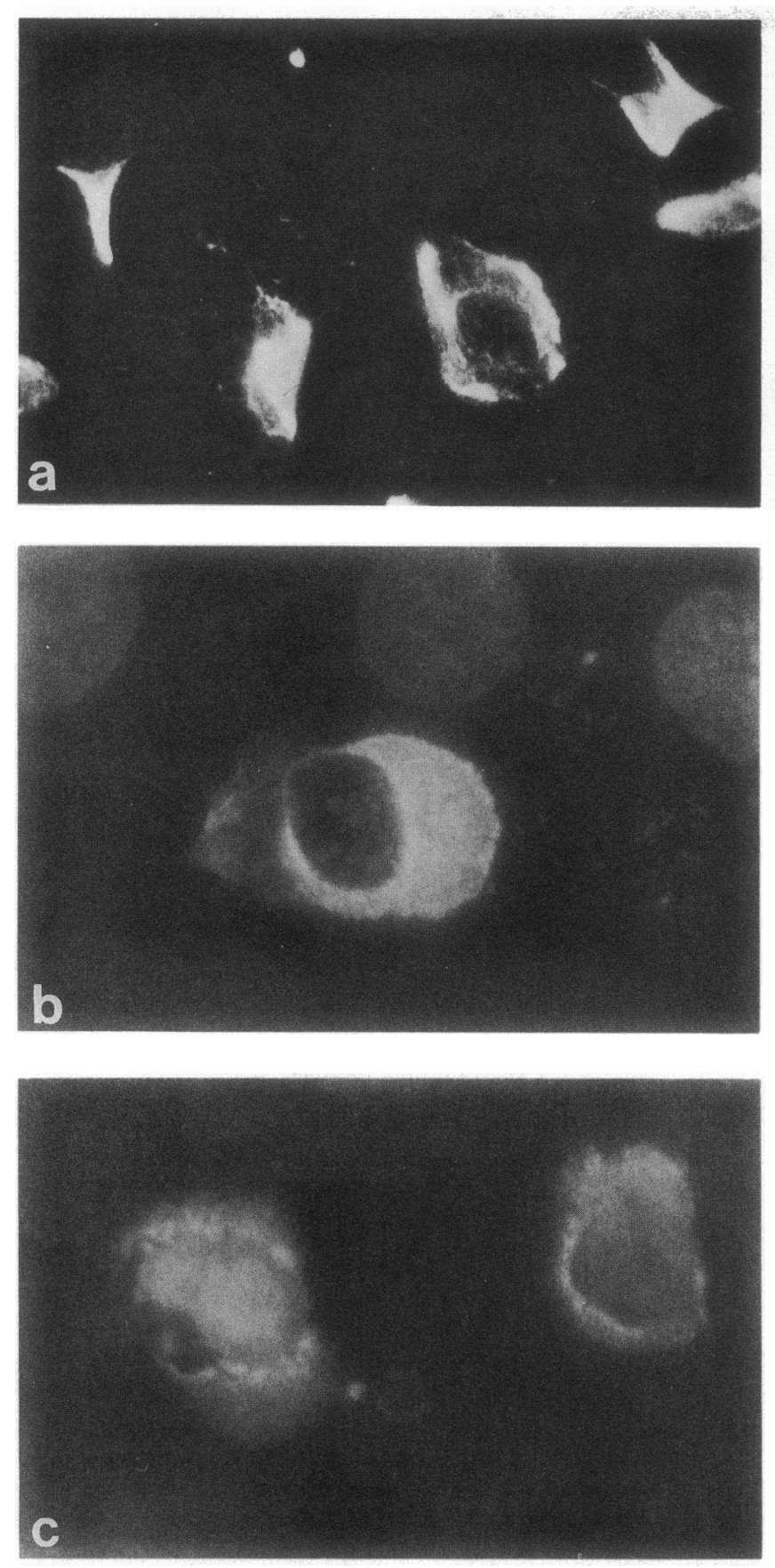

Figure 3. Immunostaining for the HTLV-I antigens. Indirect immunofluorescence on the CSCs from a HAAP patient using (a) GIN 14 (monoclonal antibody against HTLV-I core protein, gag, p19 and p28, $\times 500$ ), (b) NOR 1 (monoclonal antibody against HTLV-I core protein, gag, p24, $\times 500$ ), (c) F10 (monoclonal antibody against HTLV-I envelope glycoprotein, env, gp $21, \times 500$ ).

of FSTs, CSCs, fresh PBMCs, and fresh SFCs from RA patients, only $\beta$-actin signal was detected (lanes 13-16). From the intensities of the bands, the amount of $\operatorname{tax}_{1} / \operatorname{rex}_{1} \mathrm{mRNA}$ in the FSTs and the CSCs from HAAP patients (lanes 5, 6, 9, and 10) was equal to that of $1 \times 10^{-4}$ diluted MT-2 RNA with HTLVI-negative RNA (lane 2). From these studies, it was found $\operatorname{tax}_{1} /$ rex $_{1}$ mRNA could be expressed in articular lesions as well as
CSCs in patients with HAAP, but these signals were not detected in fresh circulated PBMCs and fresh SFCs in these patients.

To confirm further the expression of HTLV-I mRNA in non-T synovial cells, another RT-PCR to co-amplify a message specific for $T$ cells was performed. In FCTs from HAAP patients, the amplified signals of the constant region of $T$ cell receptor (TCR) $\alpha$ chain were almost the same amount of those of HTLV-I tax $x_{1} / \mathrm{rex}_{1}$. On the contrary, in CSCs from HAAP patients, the signals of TCR were hardly observed, but those of HTLV-I tax $1 /$ rex $_{1}$ were almost the same intensities as in FSTs (data not shown).

Immunostaining for the HTLV-I antigens. We next performed immunostaining to assess the expression of viral antigen in CSCs of HAAP patients. These cells did not react with anti-CD2 or anti-CD20 antibody. A part of the CSCs stained with anti-CD14 antibody, indicating they were macrophages. Most of the CSCs, which were morphologically similar to fibroblasts, were found to be strongly reacted with monoclonal antibodies against the HTLV-I core protein (gag, p19 and p28) (Fig. $3 a$, GIN 14) and against the other HTLV-I core protein (gag, p24) (Fig. $3 b$, NOR 1) as well as to be reacted moderately with a monoclonal antibody against the HTLV-I envelope glycoprotein (env) (Fig. $3 c$, F10). On the other hand, CSCs from RA patients could not be reacted with these HTLV-I monoclonal antibodies (data not shown). These suggest that the fibroblast-like nonlymphoid CSCs in patients with HAAP patients express HTLV-I viral antigens.

DNA sequence of the $p X I I$ region of HTLV-I in CSCs of $H A A P$ patients. Since the amplified DNA in the CSCs from HAAP patients hybridized with HTLV-I probes, these DNAs were likely to be HTLV-I. The DNA sequences were further analyzed to confirm this. The sequences of the pXII region in the CSCs from HAAP patients were determined by the dideoxynucleotide method. The sequences as well as those of reported HTLV family are shown in Fig. 4. The homology of the sequences derived from CSCs of HAAP patient 1 (CSC1) and patient 2 (CSC2) was $98.6 \%$. The sequence of this region of DNA derived from MT-2 cells examined in this study was the same as that derived from ATK-I (27). The homologies between the sequences generated from CSC1, CSC2 and MT-2 cells, or ATK-I were $97.5 \%$ and $99.4 \%$, respectively. Those between CSC1, and CSC2 and HTLV-II were $83.0 \%$ and $84.2 \%$, and these between CSC1, and CSC 2 and STLV were $90.6 \%$ and $92.4 \%$. The sequence homologies among various clones of HTLV-I in the pXII region were reported to range from $97 \%$ to $99 \%(27,30)$. The complete DNA sequence of a cloned provirus of HTLV-II (28) is 60\% homology with HTLV-I. The sequence homology of STLV (29) with HTLV-I is 90-95\%. Therefore the DNA sequences generated from the CSCs of HAAP patients can be variations of HTLV-I itself.

\section{Discussion}

To assess the relationship of HTLV-I infection and inflammatory arthropathies seen in HTLV-I-infected individuals, we examined affected synovial tissues for the presence of proviral DNA. We found HTLV-I proviral DNA in PBMCs and SFCs as well as $\mathrm{T}$ cell-depleted CSCs from two patients with HAAP. Furthermore, the viral gene expression in FSTs and CSCs from articular lesions was also detected. In contrast, the viral gene expression was not detected in PBMCs and SFCs from these 


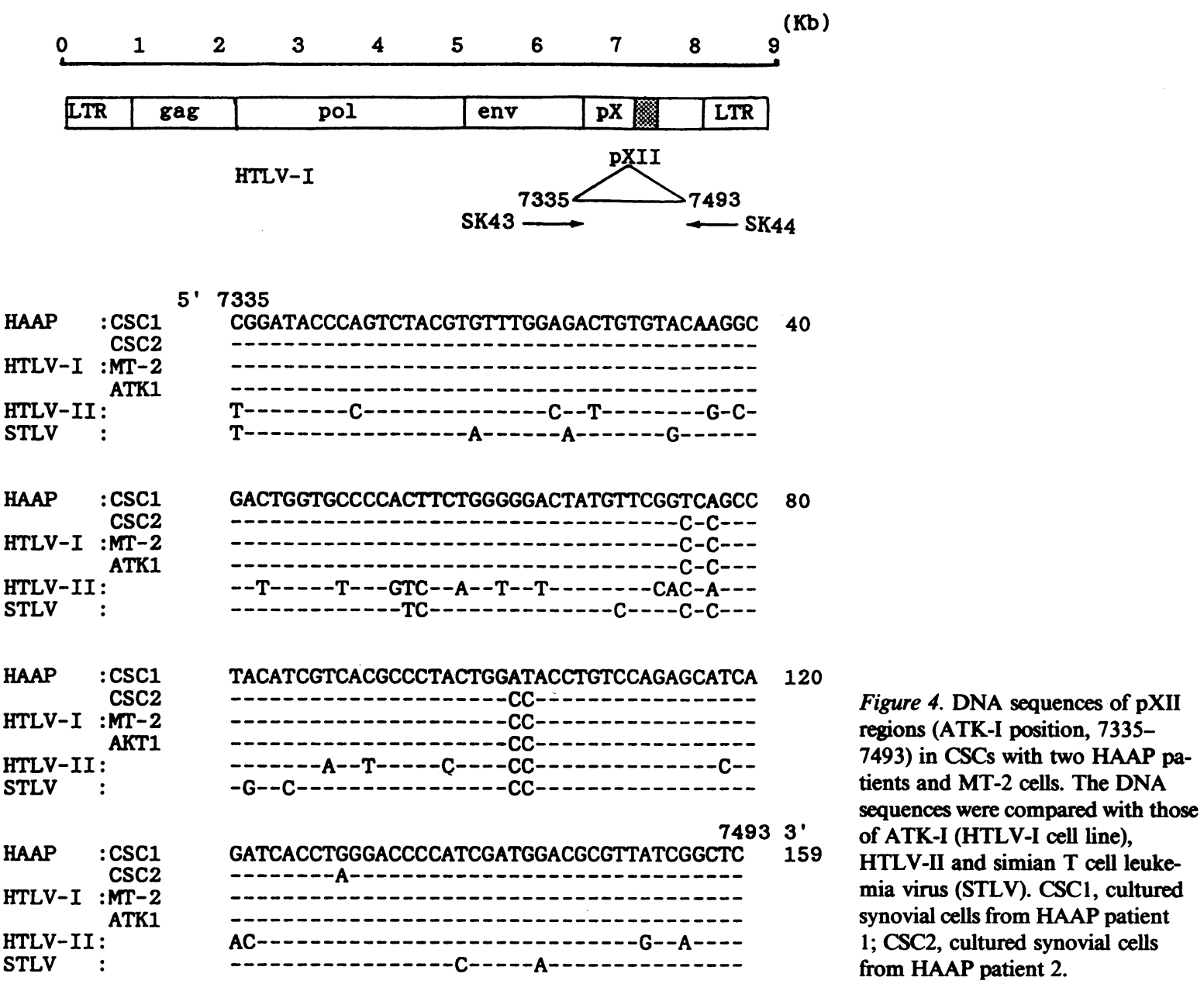

patients. Although in vitro infection of non-T cells such as B cells (31), fibroblasts (32), and endothelial cells (33) with HTLV-I has been reported, HTLV-I has previously been shown to be tropic only for $T$ lymphocytes $(1,2,12)$ in vivo. Although Kwok et al. (20) showed direct detection of HTLV-I proviral DNA in infected tissues with HTLV-I carriers, and Liberski et al. (34) also reported that HTLV-I-like viral particles were observed electron-microscopically in spinal cord tissue from an autopsy case of TSP, it is unclear which type of cells were actually infected in vivo. Reddy et al. (35) reported positive amplification of HTLV-I sequences in adherent cell populations consisting predominantly of monocytes and macrophages from patients with multiple sclerosis. However, it was also unclear whether $\mathrm{T}$ cells in these adherent cell populations were completely removed.

To estimate the amount of proviral DNA, we compared the amplified proviral DNA to the amplified single-copy human gene, HLA DQ $\beta$ (36). A titration analysis was also performed with MT-2 DNA mixed with HTLV-I-negative DNA. The amount of amplified proviral DNA in CSCs as well as PBMCs and SFCs was estimated to be about one-fifth of that of MT-2 cells by comparing the intensity of signals in the Southern blot analysis. It is impossible to obtain this amount of amplification from a small percentage of contaminated T cells in CSCs. The possibility of the contamination from exogenous DNA was also carefully excluded. DNA from patients was extracted separately from MT-2 cells on different days. Our DNA sequence study also suggests that the contamination by the MT-2 DNA cells could not contribute to the amplification. Moreover, HTLV-I sequences could not be amplified from DNAs of PBMCs, SFCs, and CSCs from two RA patients in the experiments performed at the same time. Thus, these data suggest that the HTLV-I DNA detected in this study represent the proviral DNA in the articular tissue of patients with HAAP.

It is, however, still possible that the detected HTLV-I proviral DNA in non-T cell CSCs could be due to in vitro transmission from contaminating HTLV-I-infected T cells during the short culture periods. To exclude this possibility, we preliminarily co-cultured CSCs from RA patients mixed with MT2 cells $\left(\mathrm{CSCs} / \mathrm{MT}-2\right.$ cells $\left.=5 \times 10^{-4} / \mathrm{ml} / 5 \times 10^{-4} / \mathrm{ml}\right)$ for $12 \mathrm{~d}$. These CSCs co-cultured with MT-2 cells were then examined by immunostaining analysis using the anti-HTLV-I monoclonal antibodies (GIN 14, NOR 1, and F10). However, no synovial cells were reacted to such HTLV-I monoclonal antibodies (data not shown). HTLV-I transmissibility is generally low in vitro. This transfer occurs only after long cell-to-cell co-culture of HTLV-I-producing cells with target cells (37). It is, therefore, unlikely that in vitro transmission to non-T cells in culture contributed to the amplified products obtained from CSC DNA and to the positive immunostaining with anti-HTLV-I monoclonal antibodies.

In our study, HTLV-I $\operatorname{tax}_{1} / \operatorname{rex}_{1}$ mRNA could be detected in FSTs from articular lesions but not in circulating fresh PBMCs and fresh SFCs of HAAP patients. This is the first demonstra- 
tion that HTLV-I viral expression level can be higher in the synovial lesions than in circulating fresh PBMCs in HTLV-I carriers. We previously reported that both IgM and IgG antiHTLV-I antibodies persist in the synovial fluid of the articular lesions but not in the sera in patients with this arthropathy (10). It has, therefore, been suggested that HTLV-I antigens might be continuously expressed in the articular lesions.

It is worth mentioning that an association between retrovirus infection and arthropathy with synovial hyperplasia has been described in lentiviral infections of sheep and goats (38). However, retrovirus-induced arthritis in humans is now controversial. An arthritis associated with human immunodeficiency virus (HIV) infection has been recognized as a new clinical entity (39), whereas Sokoloff reported this arthritis to be a nonspecific opportunistic infectious arthritis (40). Nevertheless, there are interesting implications for our study that Bentin et al. (41) reported that HIV-like particles could be found electron-microscopically among synoviocyte cell fragments from HIV-infected patients.

Immunohistochemical localization of HTLV-I-related antigens has been reported in the synovial tissues in RA patients (42). In these reports, the susceptibility to infection of articular tissues may indicate a role for retrovirus in the etiopathogenesis of inflammatory arthropathy.

In the present study, HTLV-I proviral DNA was detected in the SFCs from the articular lesions of HAAP patients. These HTLV-I-infected lymphocytes in the articular lesions might directly induce the inflammatory arthropathy. Preliminary phenotypic analysis of lymphocytes from the synovial tissues and SFCs by flow cytometry revealed a predominance of activated $T$ cells of both CD4- and CD8-positive populations. Salahuddin et al. (43) have reported that T cells infected with HTLV-I produced multiple cytokines, and Wano et al. (44) have demonstrated that the interleukin 1 (IL-1) gene is expressed in ATL cells. We have also shown that ATL cells in the synovial tissues constitutively produce IL-1-like factors, which promote the growth of synovial cells (9). Moreover, our preliminary experiments have demonstrated the presence of IL-1 and IL-6 activity in the culture supernatants of SFCs from HAAP patients (data not shown). These findings show the synovial lymphocytes infected with HTLV-I may be an important factor in this pathogenesis of inflammatory arthropathy in HTLV-I-infected individuals.

The $\mathrm{pX}$ sequence of HTLV-I encodes the $\operatorname{tax}_{1}$ and $\operatorname{rex}_{1}$. In the present study, $\operatorname{tax}_{1} / \operatorname{rex}_{1}$ mRNA could be detected in non-T cell population isolated from the articular tissue of patients with HAAP. Tax $_{1}$ encodes $\mathrm{p} 40^{\text {tax }}$, which has been shown to activate not only the HTLV-I gene but also a variety of cellular genes in trans, including IL-2, the IL-2 receptor, IL-3, IL-4, and lymphocyte/macrophage colony-stimulating factor (45-47). These cellular genes induced by $\mathrm{pX}$ might play a role in this inflammatory arthropathy.

In order to know whether or not the amplified DNAs really represent HTLV-I sequences, we determined nucleotide sequences of pXII region amplified from CSCs derived from HAAP patients. We found an $\sim 2.5-0.5 \%$ difference between the nucleotide sequences of the CSCs and MT-2 cells or ATK-I, suggesting that these variations in the sequence from CSCs were within those of HTLV-I itself but not from other HTLVI-like viruses. It has been reported that a single-point mutation in the coding region of $\mathrm{p} 40^{\text {tax }}$ in the $\mathrm{pX}$ region, causing a change from aspartic acid to glycine, resulted in a loss of trans- acting transcriptional activity (48), although whether such mutation has a clinical relevance is not clear. It has been reported that immunoregulatory disturbances caused by HTLV-I infection can cause inflammatory multisystem diseases, including bronchitis (6), Sjögren syndrome (7), and polymyositis (8), in addition to the HAM/TSP and HAAP. The pathological association of HTLV-I with inflammatory multiorgan diseases in HTLV-I carriers still remains to be clarified. Our study, however, suggests that the variety of clinical syndromes may be attributed to the cell tropism of HTLV-I and distribution of HTLV-I-affected cells in various organs.

\section{Acknowledgments}

We thank Dr. Keichi Hiramatsu, Juntendo University, for providing HTLV-I probes and Dr. Tomohiro Kinoshita, National Cancer Center Research Institute, for supplying $\beta$-actin primers.

\section{References}

1. Uchiyama, T., J. Yodoi, K. Sagawa, K. Takatsuki, and H. Uchino. 1977. Adult $\mathrm{T}$ cell leukemia: clinical and hematological features of 16 cases. Blood. 50:481-492.

2. Yoshida, M., M. Seiki, K. Yamaguchi, and K. Takatsuki. 1984. Monoclonal integration of human T-cell leukemia provirus in all primary tumors of adult $T$ cell leukemia suggests causative role of human $T$-cell leukemia virus in the disease. Proc. Natl. Acad. Sci. USA. 81:2534-2537.

3. Osame, M., K. Usuku, S. Izumo, N. Ijicji, H. Amitani, A. Igata, M. Matsumoto, and M. Tara. 1986. HTLV-I associated myelopathy, a new clinical entity. Lancet. $i: 1013-1014$.

4. Gessain, A., F. Barin, J. C. Vernant, O. Gout, L. Maurs, and A. G. Calender. 1985. Antibodies to human T-lymphotropic virus type-I in patients with tropical spastic paraparesis. Lancet. ii:407-409.

5. Yoshida, M., M. Osame, K. Usuku, and A. Igata. 1987. Viruses detected in HTLV-I associated myelopathy and adult T-cell leukemia are identical in DNA blotting. Lancet. $i: 1085$. (Abstr.)

6. Sugimoto, M., H. Nakashima, M. Matsumoto, E. Uyama, M. Ando, and S. Araki. 1989. Pulmonary involvement in patients with HTLV-I-associated myelopathy: increased soluble IL-2 receptors in bronchoalveolar lavage fluid. $\mathbf{A m}$. Rev. Respir. Dis. 139:1329-1335.

7. Vernant, J. C., G. Buisson, J. Magdeleine, J. DeThore, A. Jouannelle, C. N. Vernant, and N. Monplaisir. 1988. T-lymphocyte alveolitis, tropical spastic paresis and Sjögren syndrome. Lancet. $i: 177$. (Abstr.)

8. Wiley, C. A., M. Nerenberg, D. Cross, and M. C. Soto-Aguilar. 1989. HTLV-I polymyositis in patient also infected with the human immunodeficiency virus. N. Engl. J. Med. 320:992-995.

9. Taniguchi, A., Y. Takenaka, Y. Noda, Y. Ueno, K. Shitikawa, K. Sato, N. Miyasaka, and K. Nishioka. 1988. Adult T-cell leukemia presenting with proliferative synovitis. Arthritis Rheum. 31:1076-1077.

10. Kitajima, I., I. Maruyama, Y. Maruyama, S. Ijichi, N. Eiraku, Y. Mimura, and M. Osame. 1989. Polyarthritis in human T lymphotropic virus type-I associated myelopathy. Arthritis Rheum. 32:1342-1344.

11. Nishioka, K., I. Maruyama, K. Sato, I. Kitajima, Y. Nakajima, and M. Osame. 1989. Chronic inflammatory arthropathy associated with HTLV-I. Lancet. $i: 441$. (Abstr.)

12. Ikeda, M., R. Fujino, T. Matsui, T. Yoshida, H. Kodama, and J. Imai. 1984. A new aggutination test for serum antibodies to adult T-cell leukemia virus. Jpn. J. Cancer Res. (Gann). 75:845-848.

13. Ohtu, T., S. Tsugane, K. Tobinai, M. Shimoyama, S. Nanri, and S. Watanabe. 1987. Prevalence of antibodies to human T-cell leukemia virus type I and human immunodeficiency virus in Japanese immigrant clones in Bolivia and Bolivian natives. Jpn. J. Cancer Res. (Gann). 78:1347-1353.

14. Miyoshi, I., I. Kubonishi, S. Yoshimoto, T. Akagi, Y. Ohtsuki, Y. Shiraishi, K. Nagata, and Y. Hinuma. 1981. Type $C$ virus particles in a cord T-cell line derived by co-cultivating normal human cord leukocytes and human leukaemic T cells. Nature (Lond.). 294:770-771.

15. Yoshida, M., I. Miyoshi, and Y. Hinuma. 1982. Isolation and characterization of retrovirus from cell lines of human adult T-cells leukemia and its implication in the disease. Proc. Natl. Acad. Sci. USA. 79:2031-2035.

16. Blin, N., and D. W. Stafford. 1976. Isolation of high molecular weight DNA. Nucleic Acids. Res. 3:2303-2308.

17. Chomcynski, P., and N. Sacch. 1987. Single-step method of RNA isolation by acid guanidinium thiocyanate-phenol-chloroform extraction. Anal. Biochem. 162:156-159. 
18. Saiki, R. K., S. Scharf, F. Faloona, K. B. Mullis, G. T. Horn, H. A. Erlich, and N. Arnheim. 1985. Primer-directed enzymatic amplification of DNA with a thermostable DNA polymerase. Science (Wash. DC). 239:487-491.

19. Greenberg, S. T., G. D. Ehrlich, M. A. Abbott, B. J. Hurwitz, T. A Waldmann, and B. J. Poietz. 1989. Detection of sequences homologous to human retroviral DNA in multiple sclerosis by gene amplification. Proc. Natl. Acad. Sci. USA. 86:2878-2882.

20. Kwok, S., G. Ehrlich, B. Poietz, R. Kalish, and J. J. Sninsky. 1988. Enzymatic amplification of HTLV-I viral sequences from peripheral blood mononuclear cells and infected tissues. Blood. 72:117-1123.

21. Scharf, S. J., C. M. Long, and H. A. Erlich. 1988. Sequence analysis of the HLA-DQ and HLA-DQ loci from three pemphigus vulgaris patients. Hum. Immunol. 22:61-69.

22. Saiki, R. K., D. H. Gelfand, and S. Stoffel, 1988. Primer-directed enzymatic amplification of DNA with a thermostable DNA polymerase. Science (Wash. DC). 239:487-491.

23. Southern, E. M. 1975. Detection of specific sequence among DNA fragments separated by gel electrophoresis. J. Mol. Biol. 98:503-517.

24. Hiramatsu, K., J. Nishida, A. Naito, and H. Yoshikura. 1987. Molecular cloning of the cloned circular provirus of human $\mathrm{T}$ cell leukemia virus type I: a new open reading frame in the gag-pol region. J. Gen. Virol. 68:213-218.

25. Kinoshita, T., M. Shimoyama, K. Tobinai, M. Ito, S. Ito, S. Ikeda, K Tajima, K. Shimotohno, and T. Sugimura. 1989. Detection of mRNA for the $\operatorname{tax}_{1} /$ rex $_{1}$ gene of human T-cell leukemia virus type $I$ in fresh peripheral blood mononuclear cells of adult T-cell leukemia patients and viral carriers by using the polymerase chain reaction. Proc. Natl. Acad. Sci. USA. 86:5620-5624.

26. Smith, L. M., J. Z. Sanders, R. J. Kaiser, P. Hughes, C. Dodd, C. R. Connell, C. Heiner, S. B. H. Kent, and L. E. Hood. 1986. Fluorescence detection in automated DNA sequence analysis. Nature (Lond.). 321:674-679.

27. Seiki, M., S. Hattori, Y. Hirayama, and M. Yoshida. 1983. Human adult T-cell leukemia virus: complete nucleotide sequence of the provirus genome integrated in leukemia cell DNA. Proc. Natl. Acad. Sci. USA. 80:3618-3622.

28. Shimotohno, K., Y. Takahashi, N. Shimizu, T. Gojobori, D. W. Golde, I. S. Y. Chen, M. Miwa, and T. Sugiyama. 1985. Complete nucleotide sequence of an infectious clone of human T-cell leukemia virus type II: an open reading frame for the protease gene. Proc. Natl. Acad. Sci. USA. 82:3101-3105.

29. Watanabe, T., M. Seiki, H. Tsujimoto, I. Miyoshi, M. Hayami, and M. Yoshida. 1986. Sequence homology of the simian retrovirus genome with human T-cell leukemia virus type I. Virology. 144:59-65.

30. Myers, G., A. B. Rabson, S. F. Josephs, T. F. Smith, and F. Wong-Staal 1988. A compilation and analysis of nucleic acid and amino acid sequences. In Human Retroviruses and AIDS 1988. Theoretical Biology and Biophysics Publishers, Los Alamos, NM. 14-22.

31. Tomita, S., J. L. Ambrus, Jr., D. J. Volkman, D. L. Longo, H. Mitsuya, M. S. Reitz, Jr., and A. S. Fauci. 1985. Human T cell leukemia/lymphoma virus type I infection and subsequent cloning of normal human B cells. J. Exp. Med. 162:393-398.

32. Yoshikura, H. J Nishida, M Yoshida, Y Kitamura, F Takaku, and S. Ikeda. 1984. Isolation of HTLV derived from Japanese adult T cell leukemia patients in human diploid fibroblast strain IMR 90 and the biological characters of the infected cells. Int. $J$. Cancer. 33:745-749.
33. Hoxie, J. A., D. M. Matthews, and D. B. Cines. 1984. Infection of human endothelial cells by human T-cell leukemia virus type I. Proc. Natl. Acad. Sci. USA. 81:7591-7595.

34. Liberski, P. P., P. Rodgers-Johnson, G. Char, P. Piccardo, C. J. Gibbs, and C. Gajdusek. 1988. HTLV-I-like viral particles in spinal cord cells in Jamaican tropical spastic paraparesis. Ann. Neurol. 23:S185-187.

35. Reddy, E. P., M. Sandberg-Wollheim, R. V. Mettus, P. E. Ray, E. DeFreitas, and H. Koprowski. 1989. Amplification and molecular cloning of HTLV-I sequences from DNA of multiple sclerosis patients. Science (Wash. DC). 243:529-533.

36. Saito, I., B. Servenius, T. Comton, and R. I. Fox. 1989. Detection of Epstein-Barr virus DNA by polymerase chain reaction in blood and tissue biopsies from patients with Sjogren's syndrome. J. Exp. Med. 169:2191-2198.

37. Salahuddin, S. Z., P. D. Markham, F. Wong-Staal, G. Franchini, V. S. Karyanaraman, and R. C. Gallo. 1983. Restricted expression of human T-cel leukemia-lymphoma virus (HTLV) in transformed human umbilical cord blood lymphocytes. Virology. 129:51-64.

38. Kennedy-Stoskopf, S., M. C. Zink, P. E. Jolly, and O. Narayan. 1987. Lentivirus-induced arthritis; chronic disease caused by a covert pathogen. Rheumatol. Dis. Clin. North Am. 13:235-247.

39. Rowe, I. F., and A. C. S. Keat. 1989. Human immunodeficiency virus infection and the rheumatologist. Ann. Rheumatol. Dis. 48:89-91.

40. Sokoloff, L. 1990. A prospective necropsy study of arthritis in acquired immunodeficiency syndrome. Arch. Pathol. Lab. Med. 114:1035-1037.

41. Bentin, J., W. Feremans, J.-L. Pasteels, J.-P. Hauzeur, R. Nenu, and T. Appelboom. 1990. Chronic acquired immunodeficiency syndrome-associated arthritis: a synovial ultrastructural study. Arthritis Rheum. 33:268-273.

42. Ziegler, B., R. E. Gay, G. Huang, H. G. Fassbender, and S. Gay. 1989. Immunohistochemical localization of HTLV-I p19- and p24-related antigens in synovial joints of patients with rheumatoid arthritis. Am. J. Pathol. 135:1-5.

43. Salahuddin, S. Z., P. D. Markham, and S. G. Lindner. 1984. Lymphokine production by cultured human $\mathrm{T}$ cells transformed by human $\mathrm{T}$-cell leukemialymphoma virus I. Science (Wash. DC). 223:703-707.

44. Wano, Y., T. Hattori, M. Matsuoka, K. Takatsuki, A. O. Chua, V. Gubler and W. C. Greene. 1987. Interleukin I gene expression in adult T cell leukemia. J. Clin. Invest. 80:911-916.

45. Maruyama, M., H. Shibuya, H. Harada, M. Hatakeyama, M. Seiki, T. Fujita, J. Inoue, M. Yoshida, and T. Taniguchi. 1987. Evidence for aberrant activation of the interleukin-2 autocrine loop by HTLV-I encoded $\mathrm{p} 40 \mathrm{x}$ and T3/Ti complex triggering. Cell. 48:343-350.

46. Cross, S. L., M. B. Feinberg, J. B. Wolf, N. J. Holbrook, F. Wong-Staal, and W. J. Leonard. 1987. Regulation of the human interleukin-2 receptor chain promoter: activation of a nonfunctional promoter by transactivator gene of HTLV-I. Cell. 49:47-56.

47. Arai, N. D. Nomura, D Villaret, R. D. Malefijt, M. Seiki, M. Yoshida, S. Minoshima, R. Fukayama, M. Maekawa, J. Kudoh, et al. 1989. Complete nucleotide sequence of the chromosomal gene for human IL-4 and its expression. $J$. Immunol. 142:274-282.

48. Seiki, M., J. Inoue, T. Takedsa, and M. Yoshida. 1986. Direct evidence and $\mathrm{p40x}$ of human T-cell leukemia virus type is a trans-acting transcriptional activator EMBO (Eur. Mol. Biol. Organ.) J. 5:561-565. 